\title{
BMJ Open Injury from electric scooters in Copenhagen: a retrospective cohort study
}

\author{
Stig Nikolaj Fasmer Blomberg (D) , Oscar Carl Moeller Rosenkrantz, Freddy Lippert, \\ Helle Collatz Christensen
}

To cite: Blomberg SNF, Rosenkrantz OCM, Lippert F, et al. Injury from electric scooters in Copenhagen: a retrospective cohort study. BMJ Open 2019;9:e033988. doi:10.1136/ bmjopen-2019-033988

- Prepublication history and additional material for this paper are available online. To view these files, please visit the journal online (http://dx.doi. org/10.1136/bmjopen-2019033988).

Received 10 September 2019 Revised 27 November 2019 Accepted 06 December 2019

Check for updates

(C) Author(s) (or their employer(s)) 2019. Re-use permitted under CC BY-NC. No commercial re-use. See rights and permissions. Published by BMJ.

Emergency Medical Services, University of Copenhagen, Region Hovedstaden (Capital Region of Denmark), Copenhagen, Denmark

\section{Correspondence to} Mr Stig Nikolaj Fasmer Blomberg;

stig.nikolaj.fasmer.blomberg@ regionh.dk

\section{ABSTRACT}

Objective To analyse injuries related to manual and electric scooter use from January 2016 up to and including July 2019.

Setting Electric scooter rental services were launched in Denmark in January 2019. The services were provided by private companies. Although rules for handling and riding scooters have been established, no reports either before or after introduction of electric scooters anticipated the full extent of use, and injuries to riders and pedestrians.

Participants All patient records mentioning manual or electric scooters. Records were reviewed, and data were stratified according to two groups: manual and electric scooters.

Interventions A predefined survey was completed in all cases where 'scooter' was present. This contained variables such as type of scooter, type of participant, mechanism of injury, acuity, intoxication, referral to treatment facility.

Outcome measures Among incidents involving scooters, summary statistics on continuous and categorical variables of interest were reported.

Results 468 scooter-related injuries were recorded. We found that manual scooter riders were more likely to be children under the age of 15; fall alone-involving no other party; sustain contusions, sprains and lacerations; and bruise either their fingers or toes. Riders of electric scooters were likely to be 18-25 years, sustain facial bruising and lacerations requiring sutures, and be under the influence of alcohol or drugs. Non-riders of electric scooters were mostly elderly people who tripped over scooters, consequently sustaining moderate to severe injuries.

Conclusion There were two different types of population sustaining injuries from manual and electric scooters, respectively. The proportion of non-riders injured by electric scooters were surprisingly large (17\%), and while electric scooters are here to stay, several apparently preventable injuries occur as a result of reckless driving and discarded electric scooters. Current rules for usage might not prevent unnecessary accidents and secure traffic safety and the lives of older individuals.

\section{INTRODUCTION}

Transport in inner cities has become difficult, and congestion is a major problem, especially for car drivers. Electric scooters

\section{Strengths and limitations of this study}

- This is the first Danish study on injuries related to scooters and electric scooters and among the first studies internationally to describe injuries to nonriders associated with electric scooters. This study collected data on a diverse range of factors, including type of scooter, type of participant, mechanism of injury, acuity and intoxication.

- The emergency departments in Copenhagen have a referral system through the emergency medical service (EMS). Consequently, all patients must call the EMS to be referred to an emergency department. Nevertheless, a small number of patients self-present at the emergency department; these individuals are not included in the study.

- This study is based on data from the EMS. This means that data are not validated with data from the emergency medical departments, thus resulting in under-reporting of injured persons.

were introduced to address the problem. The electric scooter is an easy to use, inexpensive alternative means of inner-city conveyance. ${ }^{1}$ An application can be downloaded to a smartphone, the scooter is rented and left at the rider's destination. Different cities have used different approaches to implement this new means of transport; most cities have used the free market, whereas some have used pilot schemes allowing a small number of providers to set up in the centre of the cities. ${ }^{2-6}$ Copenhagen was among the first cities to introduce inner-city electric bike rental. First, in 1995, Copenhagen introduced the Citybike (Bycyklen), ${ }^{7}$ a free of charge, publicly available bike to use on a minor deposit (20 Danish krone, approximately $€ 2.5$ euros) which were refunded if and when the bike was returned to a designated parking point. Then, in April 2014, came a pilot scheme with electric bikes; the scheme quickly became a success. However, interest gradually declined and usage diminished ${ }^{8}$ : residents had funds to buy their own electric bikes and 
tourists found the bikes impractical. The next step came in January 2019, largely arising from public demand for increased micromobility, when Copenhagen City Council permitted three providers to equip the city with electric scooters. ${ }^{9}$ From a legal viewpoint, electric scooters are considered on a par with bicycles. The rules of usage were established in a regulation ${ }^{10}$ stating that people aged 15 years or older could use the scooters unaccompanied on the city's bicycle lanes in accordance with the rules of general traffic regulations. This meant no intoxication while scooter riding and no need for personal insurance in case of a collision. Soon the city was divided into two groups: those for and those against electric scooters. The younger adults had taken to the streets using the electric scooters at all hours of the day, taking advantage of the facility to leave the electric scooters wherever they pleased and leaving the elderly population worried about obstacles on the pavements and obstructed accesses. ${ }^{11} 12$

Irrespective of how electric scooter use has been implemented and how local authorities have tried to regulate the use, there are reports of an increasing number of personal injuries resulting from scooter use in both Denmark and other countries. ${ }^{124-6}$ In this study, we report on scooter use over 42 months including the first 7 months of the electric scooter pilot scheme in Copenhagen taken from the records of the Copenhagen Emergency Medical Services (EMS). We compare electric scooters to manual scooters, as the electric scooter is the same device, but with an electric motor and thereby higher speed and force.

\section{Setting}

The Danish healthcare system is free of charge and provides equal access for all. ${ }^{13}$ Copenhagen, the Capital Region of Denmark, is the largest of five healthcare regions with a population of 1.8 million. Copenhagen is one of the world's leading biking capitals. A unified EMS system with two telephone numbers (1-1-2 for lifethreatening cases and 1813 for non-life-threatening cases) has been created around the idea of immediately triaging patients to the most appropriate level of care at the right time in the right hospital department.

The staff handling calls to the Emergency Medical Dispatch Centre are medical professionals (nurses, paramedics and physicians) who work together, allowing transfer between systems while talking to the patient. This gives a seamless medical help system that can handle both life-threatening events and everyday medical health problems.

\section{Aims}

The aim of the study was to describe injuries related to manual and electric scooter use from January 2016 up to and including July 2019.

\section{METHOD}

We created a retrospective cohort study of the approximately four million contacts to the EMS from January 2016 up to and including July 2019. The cohort contained contacts recorded within Copenhagen EMS as an integrated point of contact for emergency patient care where the patient received medical advice, was referred to a general practitioner (GP) the same or next day, was referred to an emergency department (ED), or an ambulance was dispatched.

Among incidents involving scooters, we report summary statistics on continuous and categorical variables of interest.

\section{Data collection}

From all contacts to Copenhagen EMS, we identified those associated with scooters by querying both the integrated Computer Aided Dispatch System (CAD) Logis Solution ${ }^{14}$ and the electronic prehospital medical record from ambulances for phrases where the clinician or medically trained dispatcher had referred to 'scooter'. In Danish, the word for scooter is 'loebehjul', and we queried all records for phrases containing 'oebehj' as this combination of letters for scooter is unique in Danish and is not contained in any other Danish word.

Medical records referring to scooters were reviewed by one of the authors (OCMR) to verify eligibility and fill in a survey that systematically collected variables to be analysed, including whether the record referred to an electric scooter or a manual scooter (survey online supplementary appendix 1). All records from the dispatch system were reviewed by the first author (SNFB) applying the same survey. In online supplementary appendix 1 , the entire survey that was used to collect data from medical records is shown. We collected data on 'Type of scooter', 'Patients', 'Mechanism of injury' (rider and non-riders), 'Helmet use', 'Intoxication', 'Acuity' (on a scale 1-5 with 1 requiring the most urgent treatment), 'Injury characteristics', 'Police involvement' and 'Referral'. Persons controlling the scooter at the time of accident were defined as 'Riders', all other patients were defined as 'Non-riders', even patients who could be riding a bicycle or be non-controlling passengers on electric scooters for instance.

\section{Statistical analysis}

Descriptive analyses were performed. Absolute numbers and percentages for variables were reported. Comparative analyses were performed comparing electric scooter incidents to manual scooter incidents using non-parametric statistics. All analyses were performed using SAS Statistical Enterprise Software, V.7.11.

\section{Patient and public involvement}

No patients involved.

We followed the general data protection regulation and registered the study at the Danish Data Protection Agency. The study did not require the consent of 

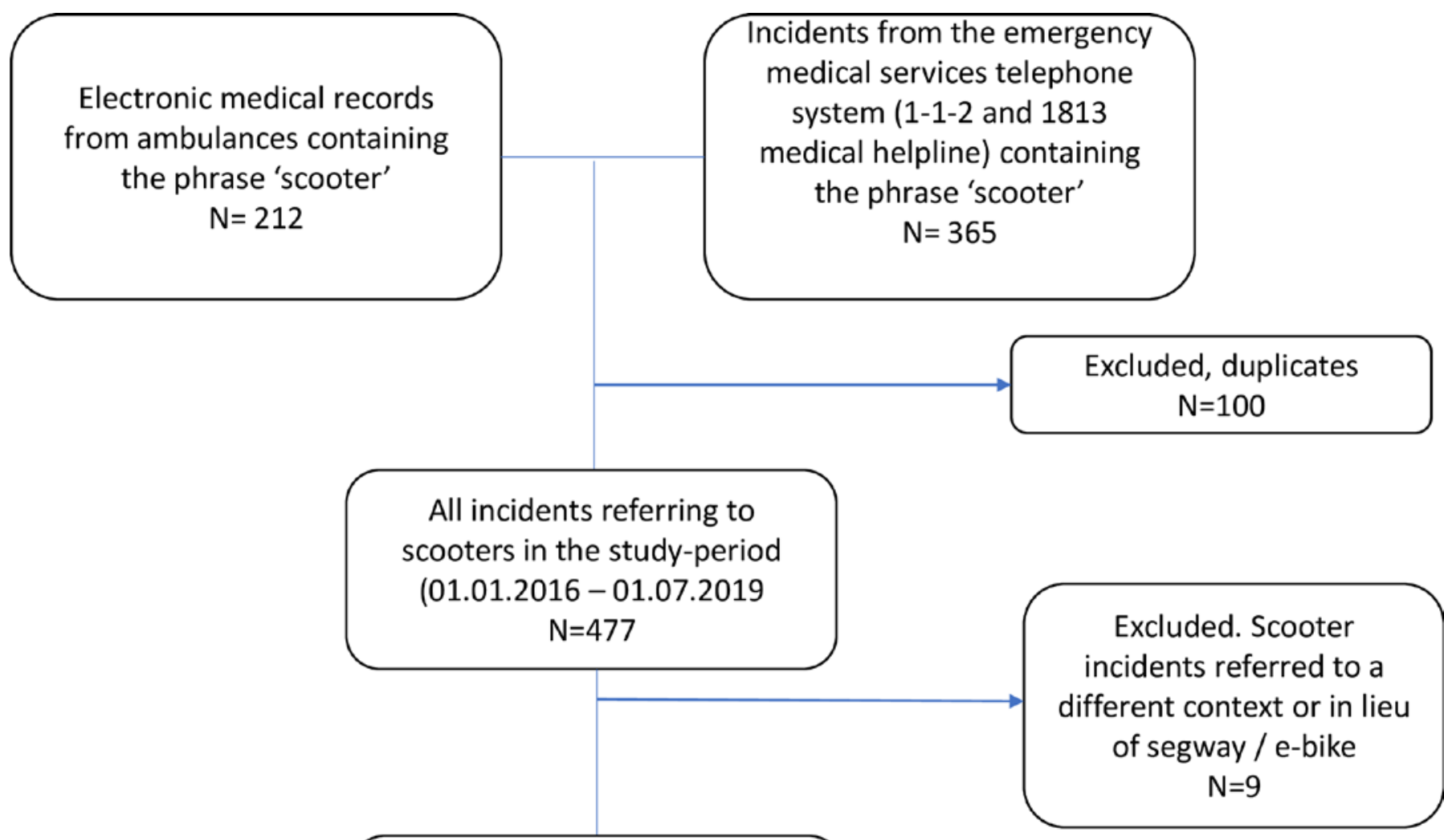

Figure 1 Study flow chart. in total, 577 records were reviewed. Of these 468 were confirmed riders of scooters and eligible for analysis.

individual patients in accordance with the Research Ethics Committee in the Capital Region of Denmark, the Danish Data Protection Agency or the Copenhagen EMS. Hence no patients have been contacted or asked to participate.

\section{RESULTS}

During the study period, 468 patients (201 (43.0\%) male, median age 12 years (IQR: 9-25 years)) contacted the EMS regarding injuries associated with either manual or electric scooter use (figure 1). The demographics and incident characteristics and comparison between injuries from manual and electric scooters, both riders and non-riders, are shown in table 1 . We found significant differences in the two cohorts of riders regarding age, mechanism of injury, ambulance use and referral to ED or GP. Also, time of day was significantly different, where a large proportion of electric riders were injured during the night. Differences in helmet use and intoxication were also highly significant. Similar analysis was performed for non-riders where no significant differences were found or reported. See table 1 for details.

Moreover, we did a comparison between manual and electric scooter riders. For manual scooter riders, most patients were under the age of 15 years (median age 10 years (IQR: 8-13years)). For electric scooter riders, most patients were between 18 and 25 years of age (median age 27 years (IQR: 22-42 years)). For non-riders injured by scooters, there was also a difference in age. For manual scooter non-riders, the median age was 35 years (IQR: 11-60); for electric scooter non-riders, the median age was 75 years (IQR: 54-78). There were 435 scooter riders (323 manual and 112 electric) and 33 non-riders (15 manual and 18 electric scooters) of whom 19 were hit by a scooter ( 9 manual and 10 electric), 13 tripped over a discarded scooter (5 manual and 8 electric) and 1 fell while getting out of a vehicle holding a manual scooter.

The majority of scooter accidents occurred between 15:00 and 23:00 hours, although many electric scooter accidents occurred between 23:00 and 07:00 hours (38 $(33.9 \%))$.

Among riders, the most common injury was from falling off the scooter (303 (93.8\%) manual and $97(86.6 \%)$ electric scooters). A few riders collided with an object (9 (2.8\%) manual and $5(4.5 \%)$ electric scooters) and the rest were hit by a vehicle or moving object (11 (3.4\%) manual and 10 (8.9\% electric scooters). Only 23 patients 
Table 1 Patient and collision characteristics for incidents associated with electric scooters in Copenhagen

\begin{tabular}{|c|c|c|c|c|c|c|}
\hline \multirow[b]{3}{*}{ Characteristic } & \multicolumn{4}{|l|}{ No (\%) } & \multirow[b]{3}{*}{ Total $(n=468)$} & \multirow{3}{*}{$\begin{array}{l}\text { P value } \\
\text { Electric riders } \\
\text { versus manual } \\
\text { riders }\end{array}$} \\
\hline & \multicolumn{2}{|l|}{ Riders ( $n=435)$} & \multicolumn{2}{|c|}{ Non-riders $(n=33)$} & & \\
\hline & Manual $(n=323)$ & Electric $(n=112)$ & Manual $(n=15)$ & Electric $(n=18)$ & & \\
\hline \multicolumn{7}{|l|}{$\begin{array}{l}\text { Demographic } \\
\text { characteristics }\end{array}$} \\
\hline$<15$ & $273(84.5)$ & $6(5.4)$ & $5(33.3)$ & $1(5.6)$ & $285(60.9)$ & $<0.0001$ \\
\hline $15-17$ & $8(2.5)$ & $6(5.4)$ & $0(0.0)$ & $0(0.0)$ & $14(3.0)$ & 0.1343 \\
\hline $18-25$ & $5(1.6)$ & $36(32.1)$ & $1(6.7)$ & $0(0.0)$ & $42(9.0)$ & $<0.0001$ \\
\hline $26-40$ & $11(3.4)$ & $31(27.7)$ & $3(20.0)$ & $2(11.1)$ & 47 (10.0) & $<0.0001$ \\
\hline $41-64$ & $14(4.3)$ & $27(24.1)$ & $3(20.0)$ & $3(16.7)$ & 47 (10.0) & $<0.0001$ \\
\hline $65-79$ & $1(0.3)$ & $2(1.8)$ & $1(6.7)$ & $7(38.9)$ & $11(2.4)$ & 0.1030 \\
\hline$>79$ & $1(0.3)$ & . & $2(13.3)$ & $3(16.7)$ & $6(1.3)$ & 0.5569 \\
\hline Missing & $10(3.1)$ & $4(3.6)$ & $0(0.0)$ & $2(11.1)$ & $20(4.3)$ & 0.8062 \\
\hline \multicolumn{7}{|l|}{ Gender } \\
\hline Female & $159(49.2)$ & $64(57.1)$ & $11(73.3)$ & $13(72.2)$ & $247(52.8)$ & 0.0995 \\
\hline Male & $152(47.1)$ & $42(37.5)$ & $4(26,7)$ & $3(16.6)$ & $201(43.0)$ & \\
\hline Missing & $12(3.7)$ & $6(5.4)$ & $0(0.0)$ & $2(11.1)$ & $20(4.3)$ & \\
\hline \multicolumn{7}{|l|}{ Accident characteristics } \\
\hline \multicolumn{7}{|l|}{ Mechanism of injury } \\
\hline \multicolumn{7}{|l|}{ Rider } \\
\hline Fall, no specific details & 303 (93.8) & $97(86.6)$ & NA & NA & NA & 0.0159 \\
\hline Collision with an object & $9(2.8)$ & $5(4.5)$ & NA & NA & NA & 0.3865 \\
\hline $\begin{array}{l}\text { Hit by vehicle or moving } \\
\text { object }\end{array}$ & $11(3.4)$ & $10(8.9)$ & NA & NA & NA & 0.0189 \\
\hline \multicolumn{7}{|l|}{ Non-rider } \\
\hline Hit by scooter & NA & NA & $9(60.0)$ & $10(55.6)$ & NA & $0.0136^{*}$ \\
\hline $\begin{array}{l}\text { Tripped over scooter in } \\
\text { road }\end{array}$ & NA & NA & $5(33.3)$ & $8(44.4)$ & NA & $0.0059^{\star}$ \\
\hline Other & NA & NA & $1(6.7)$ & $0(0.0)$ & NA & $0.5351^{*}$ \\
\hline \multicolumn{7}{|l|}{$\begin{array}{l}\text { Mechanism of ED } \\
\text { transport }\end{array}$} \\
\hline Ambulance & $131(40.1)$ & $76(67.9)$ & $8(53.3)$ & $10(55.6)$ & $225(48.1)$ & $<0.0001$ \\
\hline $\begin{array}{l}\text { Referred to ED (own } \\
\text { transport) }\end{array}$ & $144(44.6)$ & $29(25.9)$ & $4(26.7)$ & $8(44.4)$ & 185 (39.5) & 0.0005 \\
\hline GP/emergency dentist & $14(4.3)$ & & $2(13.3)$ & . & $16(3.4)$ & 0.0253 \\
\hline Selfcare & $34(10.5)$ & $7(6.3)$ & $1(6.7)$ & . & $42(9.0)$ & 0.1825 \\
\hline \multicolumn{7}{|l|}{ Time of day } \\
\hline 07:00-15:00 & $109(33.8)$ & $19(17.0)$ & $7(46.7)$ & $5(27.8)$ & 140 (29.9) & 0.0008 \\
\hline $15: 00-23: 00$ & $204(63.2)$ & $55(49.1)$ & $8(53.3)$ & $13(72.2)$ & $280(59.8)$ & 0.0091 \\
\hline 23:00-07:00 & $10(3.1)$ & 38 (33.9) & . & . & $48(10.3)$ & $<0.0001$ \\
\hline \multicolumn{7}{|l|}{ Helmet use } \\
\hline Unknown & $282(87.3)$ & $46(41.1)$ & NA & NA & NA & $<0.0001$ \\
\hline No helmet & $22(6.8)$ & $62(55.4)$ & NA & NA & NA & $<0.0001$ \\
\hline Wearing a helmet & $19(5.88)$ & $4(3.6)$ & NA & NA & NA & 0.3469 \\
\hline \multicolumn{7}{|l|}{$\begin{array}{l}\text { Drug or alcohol } \\
\text { intoxication }\end{array}$} \\
\hline $\begin{array}{l}\text { Reported by prehospital } \\
\text { personnel }\end{array}$ & $2(0.6)$ & $41(36.6)$ & & $1(5.6)$ & $44(9.4)$ & $<0.0001$ \\
\hline
\end{tabular}


Table 1 Continued

\begin{tabular}{|c|c|c|c|c|}
\hline No (\%) & & & & $P$ value \\
\hline Riders $(n=435)$ & & Non-riders $(n=33)$ & & Electric riders \\
\hline Manual $(n=323)$ & Electric $(n=112)$ & Electric $(n=18)$ & Total $(n=468)$ & riders \\
\hline
\end{tabular}

Characteristic

ers versus electric non-riders.

ED, emergency department; GP, general practitioner; NA, non applicable.
ED for manual non-riders versus electric non-riders.

were registered as wearing a helmet $(19(5.9 \%)$ manual and $4(3.6 \%)$ electric scooters). Alcohol or drug intoxication was present in 43 patients $(2(0.6 \%)$ manual and 41 $(36.6 \%)$ electric scooters).

Table 2 shows the prehospital evaluation of the injuries recorded from the prehospital medical record. Only five patients on scooters received an acuity of one to two (3 $(0.9 \%)$ manual and $2(1.8 \%)$ electric scooters). The most common injuries were contusions, sprains and lacerations (without minor head injury) with 158 (48.9\%) manual scooter riders and $30(26.8 \%)$ electric scooter riders registered. Lacerations requiring sutures were present

Table 2 Injury characteristics

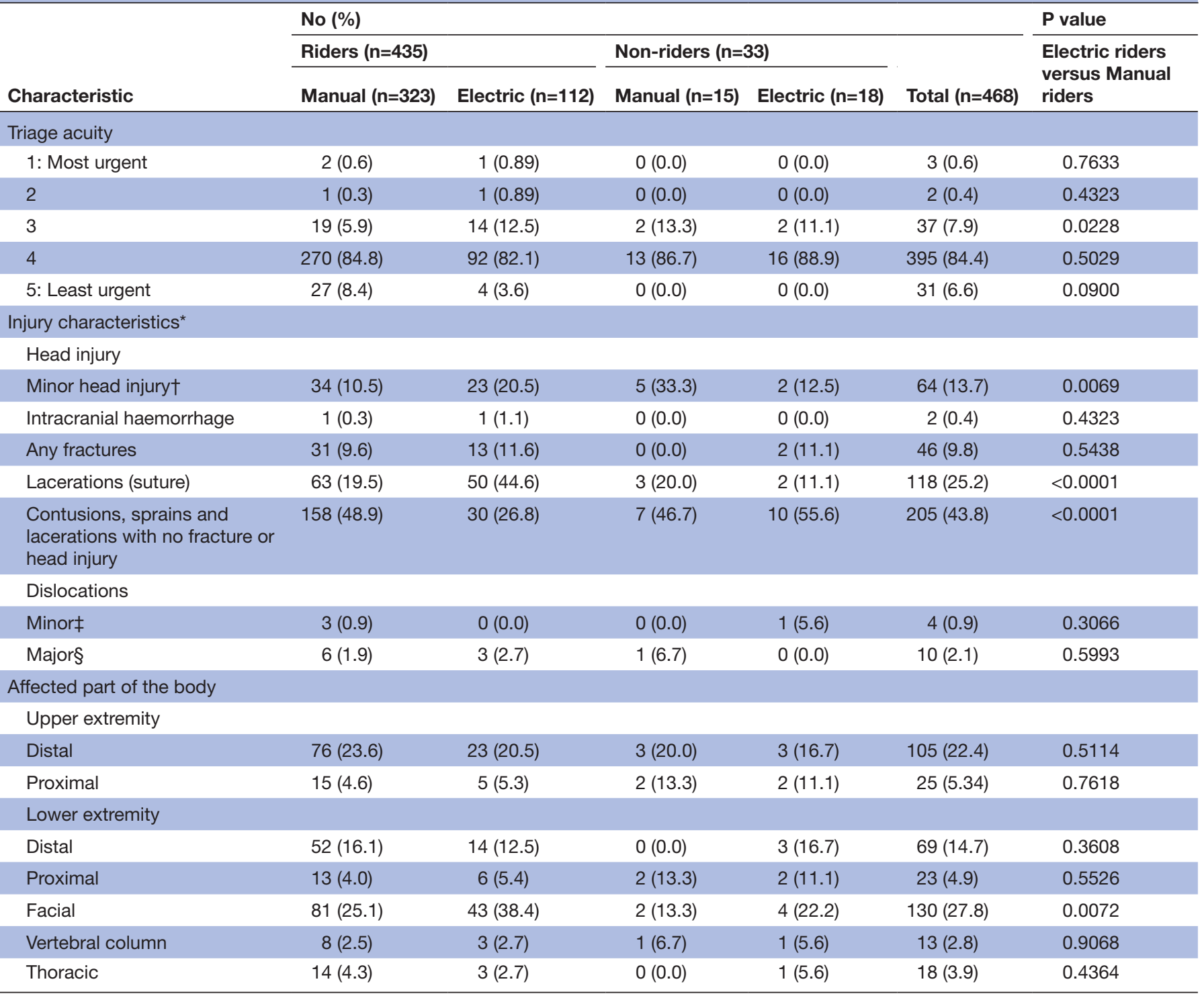

${ }^{*}$ Categories are not mutually exclusive.

†Minor head injuries include all closed head injuries without skull fracture or intracranial haemorrhage.

$\ddagger$ Minor dislocations included dislocations of the fingers or foot.

§Major dislocations include dislocations of the jaw, hips, shoulders, elbows, knees and ankles. 


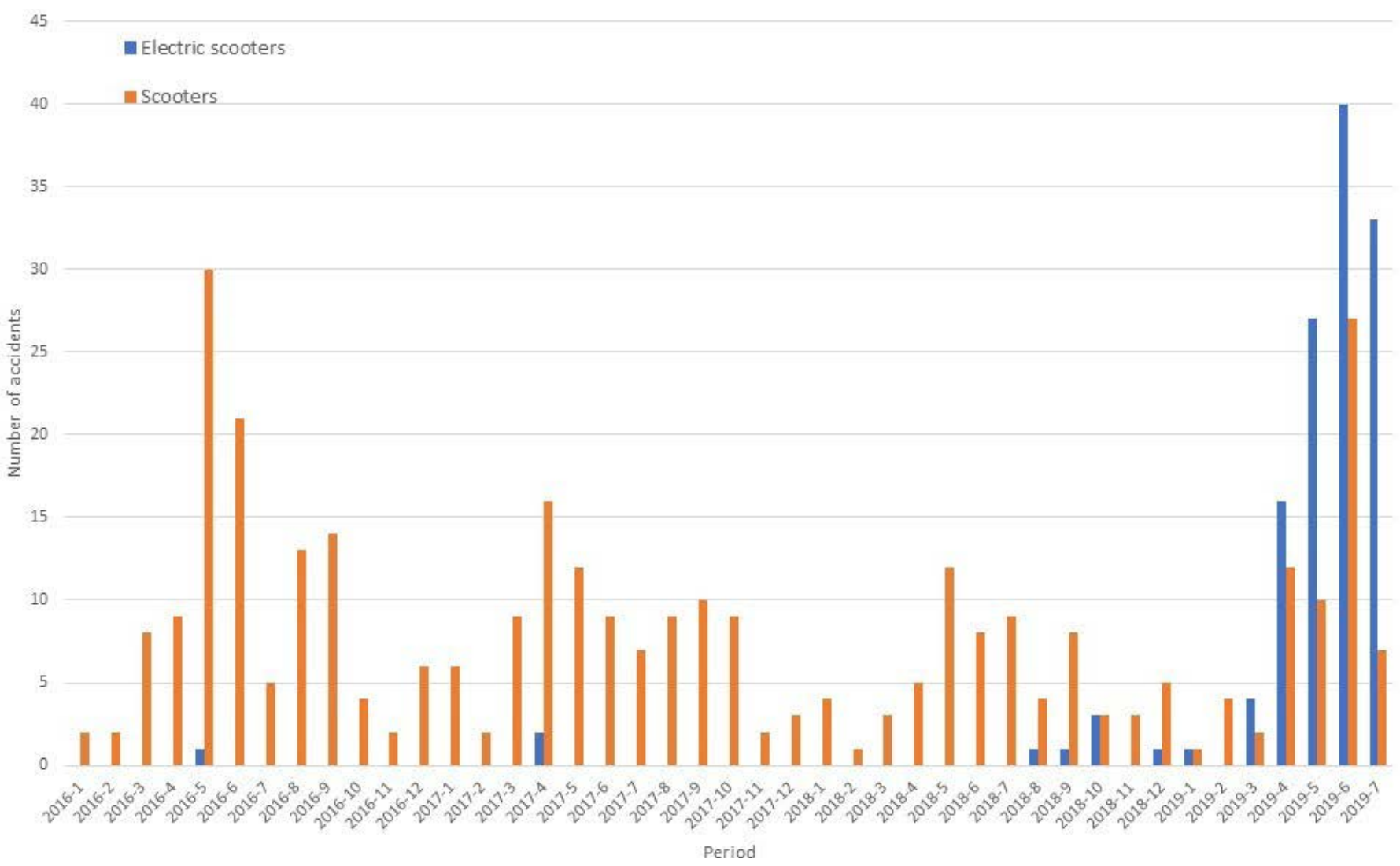

Figure 2 Distribution of injuries over time. Distribution of scooter-related injuries over time. An increase can be observed in January 2019, where electric scooters became publicly available through rental programmes.

in 63 manual $(19.5 \%)$ and $50(44.6 \%)$ electric scooter riders. Head injuries were present in $34(10.5 \%)$ manual and $23(20.5 \%)$ electric scooter riders. Two patients had major intracranial haemorrhage: a 6-year-old child who fell off his manual scooter and hit his head severely, and a 60-year-old man on an electric scooter who fell and hit his head. Fractures were common: 31 (9.6\%) among manual scooter riders and $13(11.6 \%)$ among electric scooter riders. Injury location on the body differs between the two groups. Facial injuries occurred less often in manual scooter riders $(81(25.1 \%))$ than in those on an electric scooter $(43(38.4 \%))$. Distal upper extremity injuries occurred in $76(23.6 \%)$ manual scooter riders and in 23 $(20.5 \%)$ electric scooter riders.

Figure 2 shows the distribution over time of injuries where the EMS was contacted. There was a notable seasonal variation, where more injuries occurred during the summer months than in the winter months. Moreover, for electric scooters, there was a major increase in injuries starting in January 2019 and peaked in June 2019.

\section{DISCUSSION}

Statement of principal findings: In this study of scooterrelated injuries in Copenhagen, Denmark from January 2016 up to and including July 2019, we found that injuries related to electric scooters differed from those related to manual scooters. Manual scooter riders were more likely to be children; fall alone involving no other party during the afternoon; and sustain contusions, sprains and lacerations with bruising on either their fingers or toes. Riders of electric scooters were older, usually young adults aged 18-25 years, who fell while under the influence of alcohol or drugs and who sustained facial lacerations requiring sutures.

Strengths and weaknesses of the study: Our study has several limitations. When looking for injuries arising from scooter use, we searched the records of the CAD system. The EDs in Copenhagen have a referral system through the EMS. Consequently, all patients must call the EMS to be referred to an emergency department. Nevertheless, a small number of patients self-present at the emergency department; these individuals are not included in the study.

The main strength of the study was that this is to our knowledge the first European study describing injuries from electric scooters. Further, this study is among the first studies internationally to describe injuries to nonriders associated with electric scooters.

Strengths and weaknesses in relation to other studies, discussion of important differences in results: When drawing comparisons with reports from other cities, we found a comparable match in scooter-related injuries. ${ }^{2-6}{ }^{15}$ Several electric scooter riders had bruised their faces and banged their teeth. Mayhew et al describe an 
increase of 47 CT scans over 3 months in 2018 in Auckland, New Zealand. ${ }^{4}$ Trivedi et al reported 74 CT scans over a year; they investigated the use of electric scooters during 2017-2018 in California. ${ }^{5}$ Alone, a CT scan is an expensive procedure; however, taken together with the cost of the hospital stay, the days absent from the labour market and the patients' long or short-term disabilitiesranging from fixing broken arms and legs and fixing loose or broken teeth to dealing with the consequences of head injury-this new, emerging type of injury is a very costly event.

The use of a helmet, also while riding an electric scooter, is widely discussed. ${ }^{4516}$ Before 2019, most accidents occurred among children, who bruised their hands and sometimes their feet from riding manual scooters. These accidents were mainly low energy impacts due to the scooter's limited speed, resulting in only $10.5 \%$ of riders sustaining minor head injuries. From 2019, the same device, but in an electric version, has been used by adults, and an entirely different pattern of injuries is emerging, where the faster electric scooters are resulting in high energy impacts with $20.5 \%$ of riders sustaining head injuries. Whether wearing a helmet should be mandatory has yet to be decided; however, the proportion of head injuries among electric scooter riders suggests that helmet use is recommendable, although mandation does not necessarily result in complete compliance, particularly for hired electric scooters. ${ }^{17} 18$

Meaning of the study: possible explanations and implications for clinicians and policy-makers: This study is the first European study to analyse injuries arising from electric scooter use. Few studies exist globally. In Paris and London, deaths have occurred from riding an electric scooter. ${ }^{19-21}$

The pattern of use could be seen as a development of 'playthings' for recreational use and, as such, a private affair. However, in Denmark, electric scooters are a governmental initiative introduced with a pilot scheme to be evaluated by an official board of the Police Force. It is a regulated area under the established traffic rules and regulations; therefore, it is not deemed a private matter. ${ }^{10}$ The number of deaths and major injuries must be considered when this pilot scheme is evaluated. Moreover, injuries to non-riders must also be considered. In the first 7 months that electric scooters have been publicly available in Copenhagen, the number of injuries to nonriders has surpassed that of the previous 3 years.

Under the rules for suppliers of rental electric scooters, the suppliers are obliged to collect and store the devices each night, but the seven persons, mostly older individuals, who tripped over scooters suggest a need to prevent random scooter parking. ${ }^{11222}$ The proportion of injured non-riders was lower in the manual scooter group, where non-riders accounted for $4.6 \%$ (15 of 323 incidents) of the manual accidents compared with the $16.1 \%$ (18 of 112 incidents) in the electric scooter group. This is more than a threefold increase in injuries. A solution to this problem could be to adopt the storage method used for electric bicycles (Bycykel), which must be stored in a charging station to reclaim the deposit after use. ${ }^{23}$ This minimises the number of carelessly discarded electric scooters.

As a part of the pilot scheme, there will be an evaluation in January 2020 where a board of police officials will consider information on most aspects of electric scooter usage with the aim of making future recommendations. ${ }^{24}{ }^{25}$ In this light, it would be relevant for the police to consider the pattern of injuries and the costs to the public as a whole, as well as the traffic risks and the possibility of death. Also the use of mathematical modelling to identify high-risk areas and adjust permissions accordingly could be considered. ${ }^{26}{ }^{27} \mathrm{It}$ is obvious that riding an electric scooter is not only convenient but also fun, but it should be done with respect to the order of the city, without disruption or disturbance. Many of the injuries described in this paper are preventable, and this should be considered when regulating the area insuring the fun and convenience of riding an electric scooter remain available in years to come.

\section{CONCLUSION}

There are two different types of population sustaining injuries from manual and electric scooters, with differences in both demographics and injuries. Manual riders are children who fall during the day and sustain injuries to the extremities, whereas electric scooter riders are young adults who fall on their faces, often under the influence of alcohol or drugs. Further, the proportion of non-riders injured by electric scooters constitutes a problem that needs to be addressed. While electric scooters are here to stay, several apparently preventable injuries occur as a result of reckless driving and discarded electric scooters. The current rules for usage might not prevent unnecessary accidents and secure traffic safety and the lives of older individuals.

Acknowledgements Special thanks to the ambulance staff and physicians in the emergency medical services in Denmark who collected data for this study. The documentation is essential and without it the recorded monitoring of real improvements would not have been possible.

Contributors All authors agreed on the study setup, data collection and analysis. SNFB, the first author, was involved in the data collection and drafted the manuscript; OCMR was involved in the data collection and review of the manuscript; FL reviewed the manuscript; and HCC was involved in the data collection and review of the manuscript.

Funding This work was supported by TrygFonden.

Competing interests None declared.

Patient consent for publication Not required.

Ethics approval A request was sent to the Research Ethics Committee in the Capital Region of Denmark, but approval was not needed for this study (J.number H-19045398)

Provenance and peer review Not commissioned; externally peer reviewed.

Data availability statement Data are available on reasonable request. Please email the corresponding author to request the relevant data. Please provide the authors of the article with a detailed protocol for the proposed study and supply information about the funding and resources to conduct the study. If appropriate, 
invite the original author(s) to participate in the reanalysis. If a month elapses without a response from the authors, please email the editorial office of the BMJ.

Open access This is an open access article distributed in accordance with the Creative Commons Attribution Non Commercial (CC BY-NC 4.0) license, which permits others to distribute, remix, adapt, build upon this work non-commercially, and license their derivative works on different terms, provided the original work is properly cited, appropriate credit is given, any changes made indicated, and the use is non-commercial. See: http://creativecommons.org/licenses/by-nc/4.0/.

\section{ORCID iD}

Stig Nikolaj Fasmer Blomberg http://orcid.org/0000-0002-5073-6820

\section{REFERENCES}

1 Choron RL, Sakran JV. The integration of electric scooters: useful technology or public health problem? Am J Public Health 2019;109:555-6.

2 Siman-Tov M, Radomislensky I, Peleg K, et al. The casualties from electric bike and motorized scooter road accidents. Traffic Inj Prev 2017;18:318-23.

3 Badeau A, Carman C, Newman M, et al. Emergency department visits for electric scooter-related injuries after introduction of an urban rental program. Am J Emerg Med 2019;37:1531-3.

4 Mayhew LJ, Bergin C. Impact of e-scooter injuries on emergency department imaging. J Med Imaging Radiat Oncol 2019;63:461-6.

5 Trivedi TK, Liu C, Antonio ALM, et al. Injuries associated with standing electric scooter use. JAMA Netw Open 2019;2:e187381 -e81.

6 Bresler AY, Hanba C, Svider P, et al. Craniofacial injuries related to motorized scooter use: a rising epidemic. Am J Otolaryngol 2019;40:662-6.

7 Shaheen SA, Guzman S, Zhang H. Bikesharing in Europe, the Americas, and Asia: past, present, and future. Transportation Research Record 2010;2143:159-67.

8 Behrendt M. Every city-bike is used less than once a day - Hver bycykel kører mindre end én tur om dagen. Ingeniøren. Copenhagen: The Danish society of engineers, 2014.

9 Brief from public inquiry. - Council of Copenhagen on regulation L28. Council of Copenhagen, 2018: 1-78.

10 Hansen CF. Regulation on pilot scheme for motorised scooters - Bekendtgørelse om forsøgsordning for motoriseret løbehjul. In: Transport-B-oB. First ed. Copenhagen: Retsinfo.dk, 2019.

11 Dozens of arrests in Copenhagen for drunk scooter driving: BBC com/News, 2019. Available: https://www.bbc.com/news/worldeurope-48916918 [Accessed 17 Jul 2019].
12 Herschend S. E-scooters disturb the street sweepers - had to leave their motorised street sweeper 70 times a day to remove them El-løbehjul forstyrrer gadefejerne - må ud af fejebilen 70 gange om dagen for at fjerne dem, 2019. Available: http://nyheder.tv2.dk/ samfund/2019-07-11-el-loebehjul-forstyrrer-gadefejerne-maa-ud-affejebilen-70-gange-om-dagen-for-at [Accessed 17 Jul 2019].

13 Schmidt M, Schmidt SAJ, Adelborg K, et al. The Danish health care system and epidemiological research: from health care contacts to database records]]\&gt. Clinical Epidemiology 2019;11:563-91.

14 Logis CAD. Logis solutions A/S, 2015. Available: http:// www. logiscad.com/

15 Tan AL, Nadkarni N, Wong TH. The price of personal mobility: burden of injury and mortality from personal mobility devices in Singapore a nationwide cohort study. BMC Public Health 2019;19:880.

16 Kaplan S, Vavatsoulas K, Prato CG. Aggravating and mitigating factors associated with cyclist injury severity in Denmark. J Safety Res 2014;50:75-82.

17 Haworth NL, Schramm A. Illegal and risky riding of electric scooters in Brisbane. Medical Journal of Australia 2019;211:412-3.

18 Olivier J, Radun I. Bicycle helmet effectiveness is not overstated. Traffic Inj Prev 2017;18:755-60.

19 Electric scooter rider killed in Battersea lorry crash: BBC.com/News, 2019. Available: https://www.bbc.com/news/uk-england-london48968912 [Accessed 23 Jul 2019].

20 E-scooter crashes spark call for new rules: BBC.com/News, 2019. Available: https://www.bbc.com/news/uk-england-london-49002636 [Accessed 23 Jul 2019].

21 Clercq GD. First electric scooter user killed in Paris traffic accident: Reuters.com, 2019. Available: https://www.reuters.com/article/ us-france-scooters/first-electric-scooter-user-killed-in-paris-trafficaccident-idUSKCN1TC1NU [Accessed 23 Jul 2019].

22 How safe are electric scooters. Bbc news: BBC.com/news, 2019. Available: https://www.bbc.com/news/uk-48106617 [Accessed 23 Jul 2019].

23 Bycyklen.dk, 2019. Available: https://bycyklen.dk/da/ [Accessed 17 Jul 2019].

24 Olesen OB. Suggestion to law about changes in the trafic law Forslag til lov om ændring af færdelseloven. L28. Folketingstidende: Folketingen 2018.

25 Brief from Public Inquiry - Regulation of pilot scheme for regulation on self-balancing vehilce. motorised skateboards and motorised scooters - Høringsnotat - Bekendtgørelse om forsøgsordning for selvbalancerende køretøjer og motoriserede skateboards og bekendtgørelse om forsøgsordning for motoriseredeløbehjul 2018;27.

26 Chen P, Shen Q. Identifying high-risk built environments for severe bicycling injuries. J Safety Res 2019;68:1-7.

27 Chen P. Built environment factors in explaining the automobileinvolved bicycle crash frequencies: a spatial statistic approach. Saf Sci 2015;79:336-43. 